\title{
It is a Rumour-Panic: The Media-spread of the "Blue Whale" Suicide Game in India and the Responses to it.
}

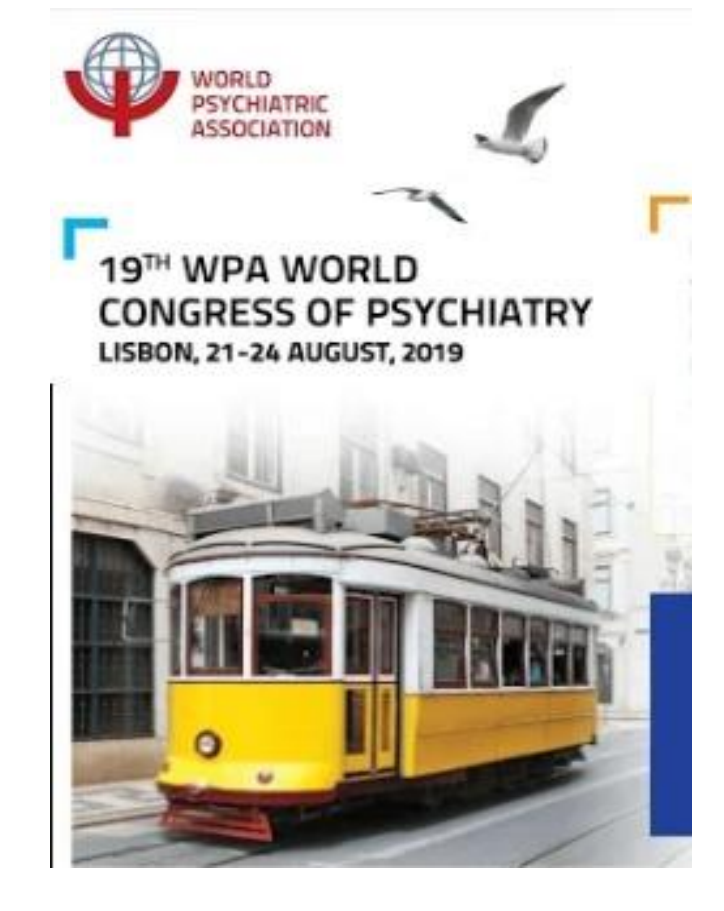

\author{
Ramkumar GS, Anvar Sadath. Dept. of Psychiatry, Gov. Medical College, Idukki, Kerala. \\ Contact email: ram3481@gmail.com

\begin{abstract}
A rumour about an internet-based "Blue Whale" suicide game has spread across the globe and teenager suicides attributed to it have been reported from many countries. Beginning on July 31, 2017, many cases were reported from India, triggering much public alarm. Based on a theory of rumour panic, this article is an exploration of its local spread in India by examining the media reports connected with it.
\end{abstract}

Widely rumoured as a danger that targets innocent teenaged players, the Internet-based "Blue Whale game," has received much media attention across the globe. The game, as reported, is in the form of a challenge which leads players to commit suicide. First reported from Russia in May 2016, its existence, however, could not be verified by any of the online fact checking agencies (e.g., www.snopes.com), and it has been called a "sensationalized fake news story" (www. saferinternet.org.uk) Nevertheless, correspondence, mainly from Asian countries, as letters to scholarly journals have raised concern by framing it as a real problem.[1-6]

A review of the national newspaper with most circulation -The Times of India (TOI), showed a high degree of attention that media gave to the game in 2017. 250 articles which covered a total of 50 incidents, reported as connected with the game could be retrieved of which 21 were completed suicides and 27 were attempts at self-harm. Headlines in the national daily presented the game and its linkage to suicide as a fact (Table $1)$.

This study is an exploration of the media spread of the game and the responses to it in the southern state of Kerala It uses a sociopsycological theory of collective anxiety and rumour panic [7] in trying to establish that the shared belief in the rumour about the game was triggered and encouraged by the media reports and mass media messages from experts and authority figures, while the behavioural responses in individuals were a consequence to it. Reports in two leading newspapers of the state (Mathrubhumi and Malayala Manorama) and select other reports from english newspapers were used for the analysis.

"Initial stage of alarmist press coverage"

This stage is characterized by media amplifying initial claims about the game.

The first report about an event from Kerala appeared on August $3^{\text {rd }}, 2017$ in Malayala Manorama. It was titled "Controversial Game in Kerala too, Police in Pursuit," the subheading being "the game has been downloaded over 2000 times as per the police." It reported that parents on checking children's mobile phones found that they were playing the "deadly game." This report is supplemented on the same day by an open editorial by a psychiatrist titled "Killer Cyber Games." On next day, Mathrubhumi publishes a report titled "School children in Kerala too onto daring bloody game" along with an open editorial by a cyber-expert titled "Online Deadly Games." The print report is accompanied by a color photograph of a teen's forearm with cut marks.

"The stage of escalating alarmist press reports"

More reports quoting authority figures giving signals about the game's existence are published.

An advisory issued by the police enumerates the tasks of the game and claimed that there were "several addicts among adolescents." Parents were instructed to "remove" such games from their computers and smartphones. The Government submits a request before the Central government of India to "officially block the online game." and a government health-care institution announces counseling services to support the victims (Malayala Manorama. August 13, 2017). Regional television news channels soon air breaking news on Blue Whale 'victims' in Kerala. Based on these reports of suicides, the Child Rights Commission of the state registers a case.

The skeptical stage"

Articles that questions the existence of the game are published.

An article published early during the incident debunks it as "The report - claiming 2000 downloads is a hoax as the police have not confirmed any such cases till date" (TOI, August 5, 2017). By August 18, most major newspapers report a statement by a senior Inspector General of police that the Blue Whale game could not be traced in Kerala. A digital security expert called it "fake news." A case under IT act was charged against a youth who faked on Facebook that he was playing the game by uploading pictures of cut marks in the arm (Mathrubhumi August 19, 2017). Meanwhile news on the technical investigation undertaken by the central govt. agency which could not find any involvement of a game in the suicide incidents is reported. With such reports coming in, public skepticism becomes the new norm and further reporting on the Blue Whale dies out.

\section{Sociopsychological Interpretation \\ Cause of rumours:}

The belief in the threat rumour was given authenticity by several authority figures in the community. The initial responses to the threat from such authorities in Kerala were as if it was a reality. What followed was a further validation of the presence of a risk by experts with media presence and governmental agencies. Finally the narrative changed when skepticism was expressed in media reports. The prevailing context of the increasing use of smartphones and internet in India and the anxieties surrounding youth's engagement with it, provided the backdrop for the genesis such rumours. Law enforcement often follow philosophy of 'better safe than sorry' and air warnings without fact check, thus giving credence to rumours

Causes of individual behavioral responses

Given that the background rates of self harm and suicides are high in Kerala many cases were wrongly attributed to the game. As some children who had never used the internet were being reported as affected by the game, a case of copy cat effect (Werther effect) can be attributed.

Table 1: Headlines in national daily which presented Blue Whale linkage to the suicides and suicide attempts as a fact.

Blue Whale game Does Exist, finds AIIMS [All India Institute of Medical Sciences]

Blue Whale Claims First Life in MP [Madhya Pradesh]

Blue Whale Game: MP Teen Jumps in Front of Train.

Student Ends Life in Damoh, Blue Whale Game Claims Another Life

19-year-old Saved From Blue Whale Last Plunge

Young minds in Blue Whale trap: Two More Fall Prey to Challenge

\section{Cops Rescue 15-yr-old Blue Whale Gamer}

Suicide Bid Triggers 'Blue Whale' Rumor

\section{Conclusion}

We have looked at the spread of the idea of Blue Whale game in India as a rumour-panic. An alarmist press coverage, escalated further by knee-jerk mass-media messages from professionals and authority figures gave away strong signals of its existence. This proved to be counterproductive as it produced game-related emulative behavioral responses in individuals, which further fed the news cycle. The specific context in India of the recent penetration of internet and smartphones and the collective anxieties surrounding it provided the background for the spread of the rumour. An imitative contagion of self-injury and suicide could be implicated in this case due to undue publicity accorded to the game in the emergency responses. Preventive mass-media counter responses need to balance fact-check and risk communication. Media personnel needs to adhere to guidelines on suicide reporting to avoid imitative contagion effects. 